\title{
QUANTIFICATION OF SEDIMENT CONCENTRATIONS AND FLUXES FROM ADCP MEASUREMENTS
}

\author{
JEROEN H. AARDOOM \\ AQUA VISION BV \\ SERVAASBOLWERK 11, 3512 NK UTRECHT, THE NETHERLANDS \\ J.AARDOOM@AQUAVISION.NL
}

\begin{abstract}
There are numerous reasons to measure sediment concentrations in the water column. It can be because a harbour is located at a tidal river, where sediment transport and deposition are major factors for maintenance of channels and harbours. Or it can be the local authorities that demand a strict control of the environment during dredge operations.

The first reason requires constant monitoring of the suspended sediment concentration (SSC), at least over tidal periods. For the latter one you must be able to intervene in case of unacceptable disturbances to the surrounding environment occur. For this reasons the monitoring results must be available in real time. This paper presents a case study in which the sediment behaviour in the river Weser is monitored during a tidal period.
\end{abstract}

\section{Introduction}

Sediment transport in tidal rivers is a critical component to many coastal and waterway engineering problems: Examples include sedimentation in navigation channels, sand transport in the littoral zone and sediment re-suspension during dredging operations or due to natural processes. Sediment management tools are of fundamental importance for harbour and water authorities to reduce the costs for maintenance dredging and waterway building activities. This is underlined by the fact that the further extension of many navigation channels is planned in Europe and worldwide to meet the requirements of new (SuezMax) container ship generations. Reliable in situ data of sedimentation rates and suspended sediment concentrations (SSC) are a precondition to understand the mechanisms that control sediment transport. Regarding the measurement of SSC, both optical and acoustic devices have their pros and cons. In general, optical devices are successfully used for measurements of fine-grained sediments. They feature a nearly linear response to sediment concentrations spanning more than three orders of magnitude, which is advantageous in natural systems where concentrations can vary widely. However, optical measurements have to be regarded as point a measurement because of the strong signal decay with range and due to the nephelometer scattering, which restricts either the temporal or spatial resolution of the SSC measurement. Acoustic devices are capable of measuring SSC from a 
distance, at a high temporal and spatial resolution. Disadvantage of using acoustic devices is the dependence on sediment properties such as particle size distribution. The backscattered intensity from a homogeneous sediment suspension ensonified by an acoustic device is proportional to the product SSC $\cdot \mathrm{f}^{2} / \mathrm{a}$, where $\mathrm{f}$ is the particle form factor and a the particle radius (LYNCH et al. 1994). For particles that are small compared to the acoustic wavelength, the Rayleigh scattering law applies. Here $\mathrm{ka} \ll 1$ (where $\mathrm{k}$ is the acoustic wave number) and $\mathrm{f}^{2} / \mathrm{a}$ reduces to $\mathrm{a}^{3}$ (RAYLEIGH 1945). For increasing particle size in the regime where ka is close to unity or larger, the sensitivity of the backscattered intensity to particle size decreases. Hence, the acoustic response generally grows more rapidly with size for smaller particles. Starting from the complementary characteristics of optical and acoustic devices we developed a software tool to complete a sediment monitoring system for real-time quantification of SSC. The software, VISEA$\mathrm{PDT}^{\odot}$ (PDT stands for 'Plume Detection Toolbox'), is based on simultaneous ADCP and OBS measurements. Additional sensors can be hooked for additional information (e.g. GPS, STD, CTD, LISST, etc.). VISEA-PDT ${ }^{\odot}$ uses OBS and possible other input for real-time conversion of ADCP data to SSC. During post processing lab results of local samples (SSC and grain size distribution) can be used to validate the real-time calibration. On the basis of a case study in the river Weser the sediment monitoring system is demonstrated here.

\section{Acoustic formulation}

ADCP backscatter of sound from suspended sediment can be modeled with the sonar equation (MEDWIN \& CLAY 1998). It appoints a balance of the difference between emitted and received energy and the energy lost during the round trip of the acoustic pulse. Absolute calibration requires a complete characterization of the transmit and receive circuit of the instrument. This includes the parameters acoustic transmit power, transmit pulse length, transducer efficiency, acoustic receive sensitivity and temperature sensitivity. To quantify the relationship between these variables affecting the backscatter, a working version of the sonar equation in units of decibel was formulated (DEINES 1999):

$S_{v}=C+10 \log _{10}\left[\frac{T_{T} R^{2}}{L P_{T}}\right]+2 \alpha R+K_{c}\left(E-E_{r}\right)$

Herein, $\mathrm{Sv}$ is acoustic backscatter $[\mathrm{dB}], \mathrm{C}$ is a constant $[\mathrm{dB}], \mathrm{T}_{\mathrm{T}}$ is the temperature of the ADCP transducer $\left[{ }^{\circ} \mathrm{C}\right], \mathrm{R}$ is the (slant) range along the beam to the scatterers $[\mathrm{m}], \mathrm{L}$ is the transmit pulse length $[\mathrm{m}], \mathrm{P}_{\mathrm{T}}$ is the transmit power [W], $\alpha$ is the attenuation coefficient $[\mathrm{dB} / \mathrm{m}], \mathrm{K}_{\mathrm{c}}$ is a scale factor $[\mathrm{dB} /$ count $], E$ is the relative backscatter equal to echo intensity [count] and $\mathrm{E}_{\mathrm{r}}$ is the received noise [count]. The values of $\mathrm{C}, \mathrm{T}_{\mathrm{T}}, \mathrm{R}, \mathrm{L}$ and $\mathrm{P}_{\mathrm{T}}$ are recorded by the ADCP or provided by the factory. E is derived from the Received Signal Strength Indicator (RSSI) of the receivers. Its real-time reference level is denoted $\mathrm{E}_{\mathrm{r}}$, the noise value when there is no signal present. It may be obtained from the RSSI at the end of a profile. 
A typical value of $E_{r}$ is 40 counts. The RSSI output is measured in counts that are proportional to the logarithm of power and can be converted to $\mathrm{dB}$ units by the scale factor $\mathrm{K}_{\mathrm{c}}$. This factor has values ranging from 0.35 to 0.55 and is typically $0.45 \mathrm{~dB} /$ count. The attenuation coefficient $\alpha$ is the sum of water absorption $\left(\alpha_{\mathrm{w}}\right)$ and particle attenuation $\left(\alpha_{\mathrm{s}}\right)$. FRANÇOIS \& GARRISON $(1982 \mathrm{a}, \mathrm{b})$ summarized the empirical research on water absorption.

Particle attenuation is the spreading and absorption of acoustic energy by particles in the water. The attenuation by suspended sediment is parameterised by (URICK 1948). Using, the acoustic frequency $[\mathrm{Hz}]$, the sediment density $[\mathrm{kg} / \mathrm{m}]$, the water density $[\mathrm{kg} / \mathrm{m}]$, a particle diameter $[\mathrm{m}]$ and the kinematic viscosity of water $\left[\mathrm{m}^{2} / \mathrm{s}\right]$ according to VAN RIJN (1993). $\rho_{\mathrm{w}}$ is calculated based on salinity, temperature and depth according the well-known international equation of state of seawater (UNESCO 1981). All described parameters can be imported into VISEA-PDT ${ }^{\odot}$, either as a profile or fixed value. Fixed values can be used when no profile of CTD data is available. In this case temperature, salinity and speed of sound are calculated from the ADCP data. When CTD data are available these profile data can be used for more accurate range normalization. VISEA-PDT ${ }^{\odot}$ is able to process data from any external device. The result of the range and instrument normalization is $\mathrm{S}_{\mathrm{v}}$ that is converted to SSC by means of reference measurements of SSC. Figures 2 to 7 exhibit the processing steps from relative backscatter to SSC.

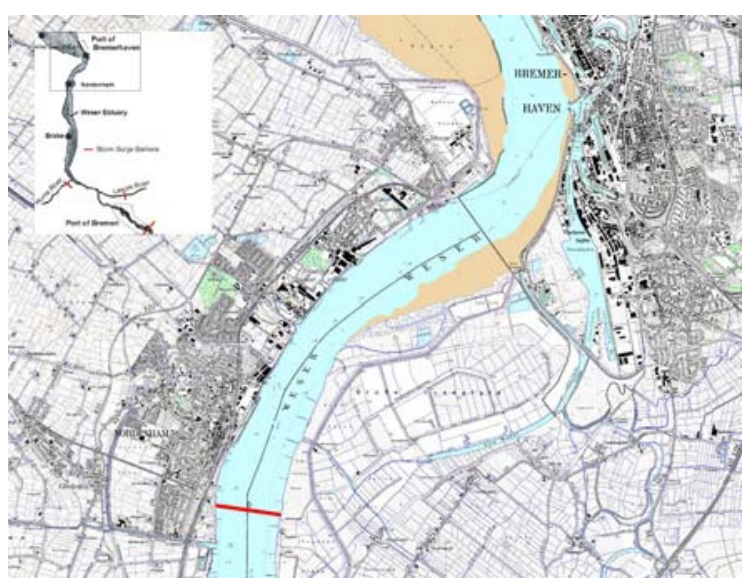

Fig. 1: Overview of Weser estuary with measurement location near Nordenham.

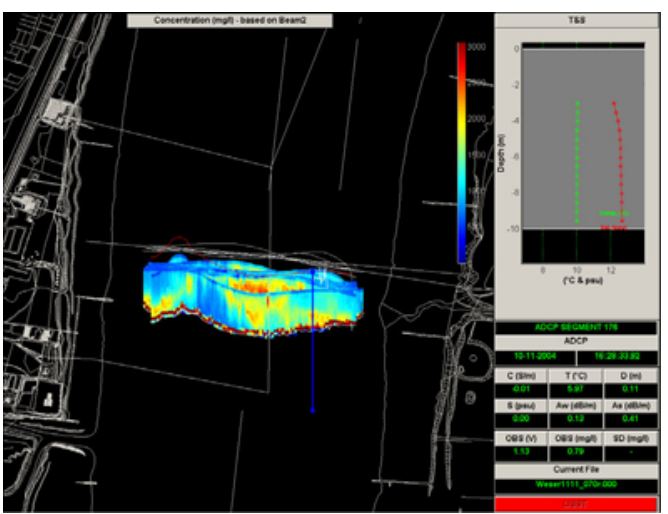

Fig. 2: Three-dimensional SSC values in the main window of VISEA-PDT ${ }^{\odot}$. The profile plot in the upper right hand corner shows data of $T$ and $S$. Numerical information of relevant parameters are presented in the lower right corner. 


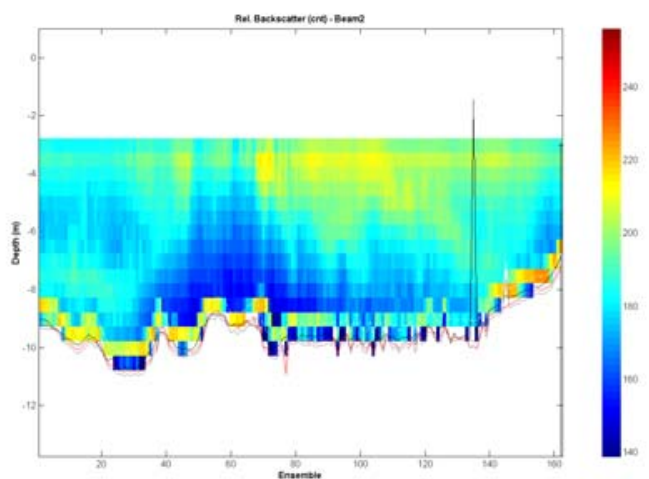

Fig. 3: Measured relative backscatter expressed in counts, equal to $\mathrm{E}$ in equation (1). Although $\mathrm{E}$ reflects $\mathrm{SSC}$ in a certain way it cannot be straightforwardly transformed towards SSC.

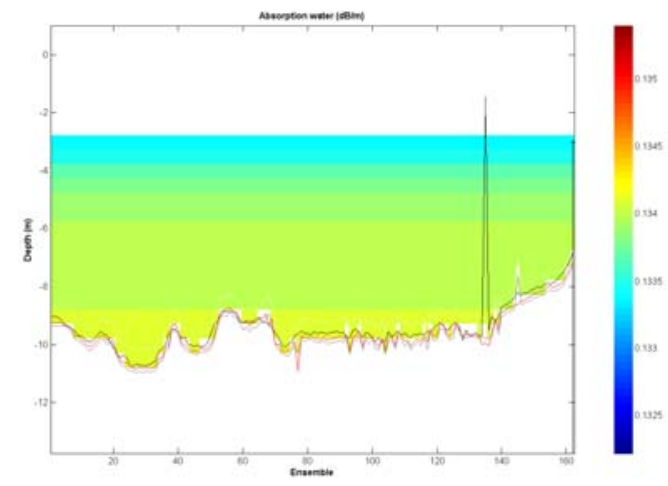

Fig. 4: Water absorption, equal to $\alpha_{w}$ in equation (2). Used for compensating acoustic energy losses due to molecular transfer of acoustic energy to heat.

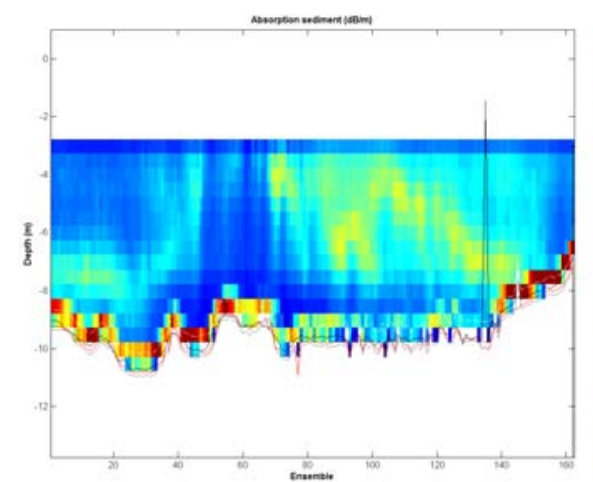

Fig. 5: Particle attenuation, equal to $\alpha_{s}$ in equation (4).This value is used for compensating acoustic energy losses due to the spreading and absorption of acoustic energy by particles in the water.

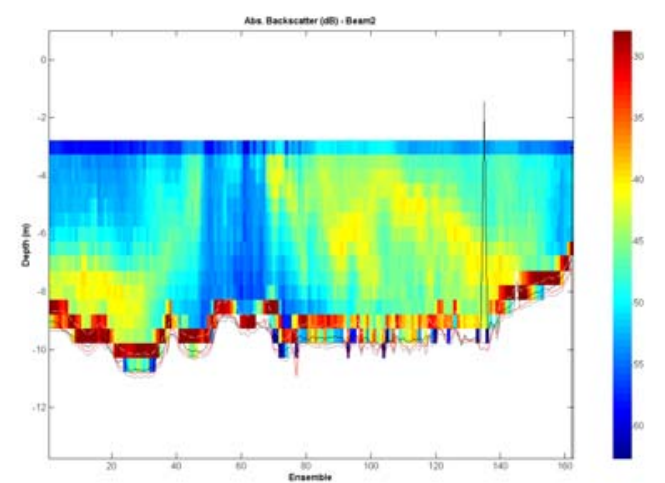

Fig. 6: Range and instrument normalized absolute backscatter in $d B$, equal to $S_{v}$ in equation (1), derived from signal processing according to the described theory.

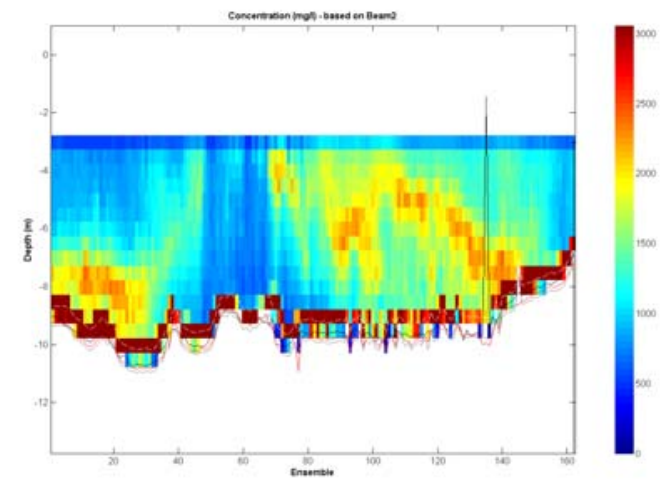

Fig. 7: Resulting SSC as converted from $S_{v}$ in real-time by means of OBS data. Note the difference with the uncorrected relative backscatter in Figure 1.

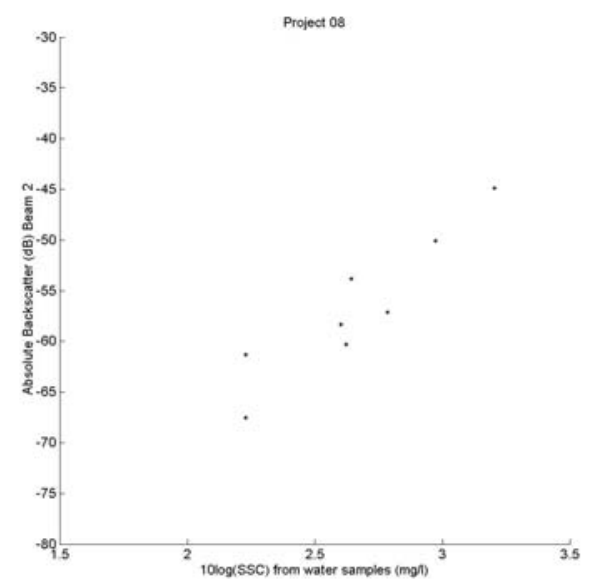

Fig. 8: Relation between SSC and the ADCP backscatter for one of the hourly subprojects. 


\section{Weser measurements}

On 10 November 2004, a 13-hour SSC measurement campaign has been performed in the tidal river Weser near Nordenham. Figure 1 shows an overview of the measurement location in the river Weser near Nordenham. The test was organized by the coastal department of the German 'Bundesanstalt für Wasserbau' (BAW). VISEA-PDT ${ }^{\odot}$ was used for the real-time quantification of sediment concentrations and fluxes. Over a period of 13 hours, SSCs were monitored by moving boat measurements with survey vessel 'TIDE' of the 'Wasser- und Schiffartsambt Bremerhaven'. The vessel was equipped with a $600 \mathrm{kHz}$ ADCP of RD Instruments and a pre-calibrated multiparameter probe for measurement of optical backscatter, conductivity, temperature and depth. Moreover a Laser In-Situ Scattering and Transmissiometer (LISST) instrument and an automated water-sampling pump were used. A total of 89 water samples were taken and analyzed afterwards in a lab to determine the SSC values and particle size distribution.

\subsection{Calibration}

The ADCP backscatter is processed and converted to SSC by means of CTD data and reference measurements of SSC. OBS data were used for the real-time calibration of the ADCP backscatter. During post-processing this real-time calibration is optimized by means of the lab results of SSC and particle size distribution analysis of the water samples. The lab results are the ground truth and used for the final calibration here. However, backscatter and therefore SSC is dependent on particle attenuation and particle attenuation is dependent on SSC. For this reason the SSC values have to be optimized using an iterative calculation procedure. VISEA-PDT ${ }^{\odot}$ starts from the absolute backscatter in the first ADCP bin and calculates SSC using a standard calibration relation. For calculation of absolute backscatter in the first ADCP bin, the particle attenuation is not taken into account. Acoustic loss is only based on acoustic spreading and water absorption. The resulting value for SSC is used for calculation of the particle attenuation. This particle attenuation is used to complete the range normalization and obtain a corrected absolute backscatter. This process is repeated until SSC is optimized. This SSC value for the first ADCP bin is used to calculate the sediment attenuation and SSC value in the second ADCP bin. This process is continued downwards for optimizing SSC values for the whole profile. The conversion process takes the influences on sound absorption by variable sediment concentrations in different layers into account. The calibration yields a relation between ADCP backscatter and SSC gained from calibrated OBS. Since the ADCP backscatter is dependent on sediment properties the LISST is used to measure grain size distributions. However, also other sediment properties (e.g. particle form) may influence the backscatter. Therefore a separate backscatter calibration is formulated based on the calibration measurements of 12 subprojects for each hour. The relation between the SSC results from the water samples and the ADCP backscatter (in $\mathrm{dB}$ ) is presented for one of the subprojects in Figure 8. 
The relation in Figure 8 can be formulated as:

$$
10 \log (\text { SSC })=A \cdot \text { Backscatter }+B
$$

In general, it can be concluded that $\mathrm{A}$ and $\mathrm{B}$ vary in time and that relations show a relatively good correlation $(r \geq 0.8)$. In order to visualize the variation, $A$ and $B$ are presented in Figure 9 together with the measured water levels at the measuring site Nordenham. The figure shows the variation of A and B varies with the tidal phase. During the flood and ebb currents the values of A and B increase as a result of changing sediment properties at the measurement site. This observation justifies the separate calibration calculations for each of the subprojects.
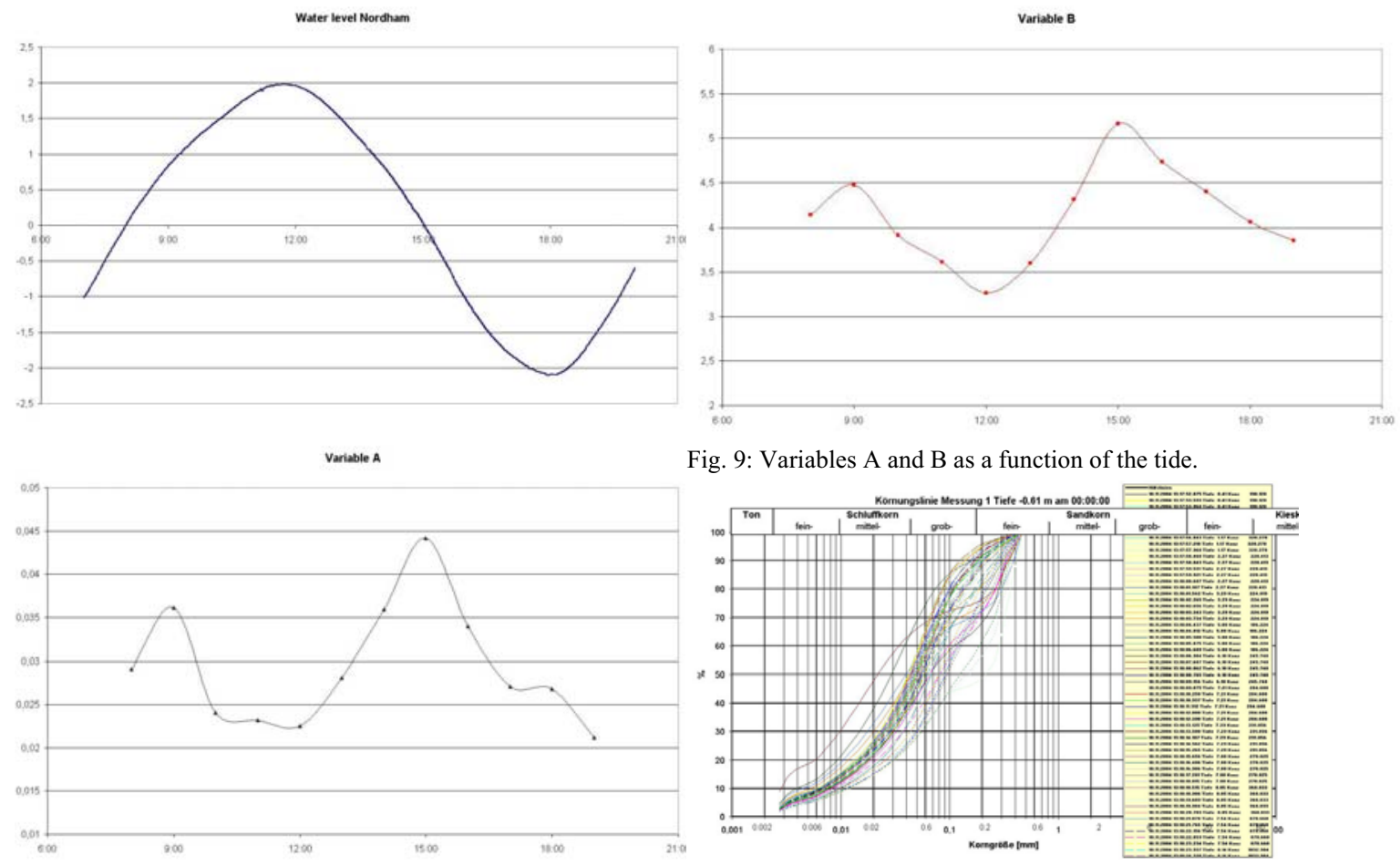

Fig. 9: Variables A and B as a function of the tide.

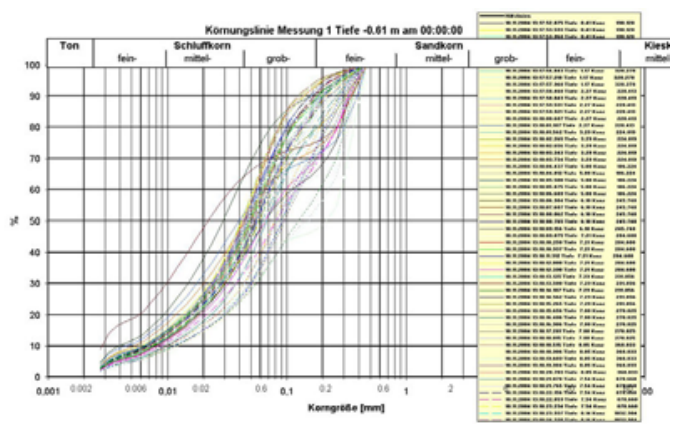

Fig. 10: Grain size distributions of Weser sediments.

\section{Sediment behavior in the river Weser}

For all transect measurements, SSC is calculated from the backscatter data according the correlation variables of each subproject. Moreover, the concentrations can be converted to sediment fluxes by making use of the simultaneously measured discharge.

\subsection{Concentrations}

Sediment concentrations of more than $1200 \mathrm{mg} / \mathrm{l}$ occur during the maximum flood current. At the end of the flood period the concentrations decrease to below 300 $\mathrm{mg} / \mathrm{l}$ in the upper part of the water column and $600 \mathrm{mg} / \mathrm{l}$ in the lower part of the 
water column. At the beginning of the ebb period the concentrations decrease to about $50 \mathrm{mg} / \mathrm{l}$ near the water surface and $150 \mathrm{mg} / \mathrm{l}$ near the riverbed.

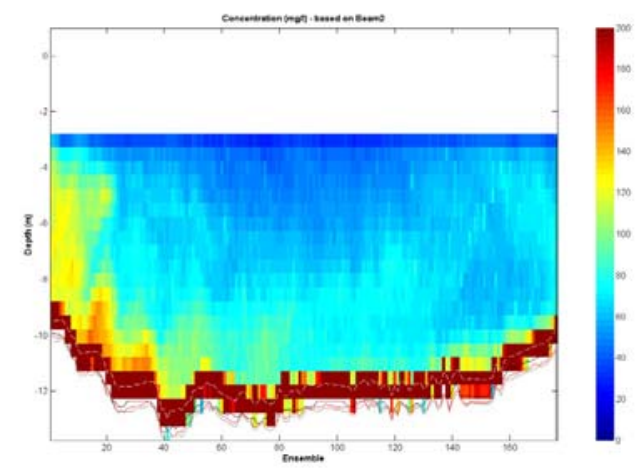

Fig. 11: Concentrations at the first part of the ebb period.

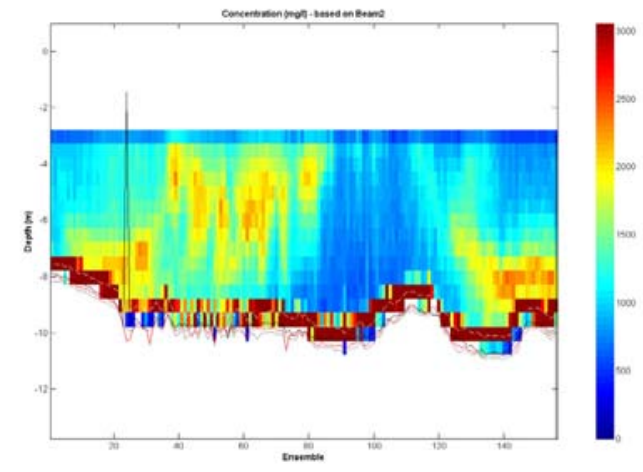

Fig. 12: Concentrations at the second part of the ebb

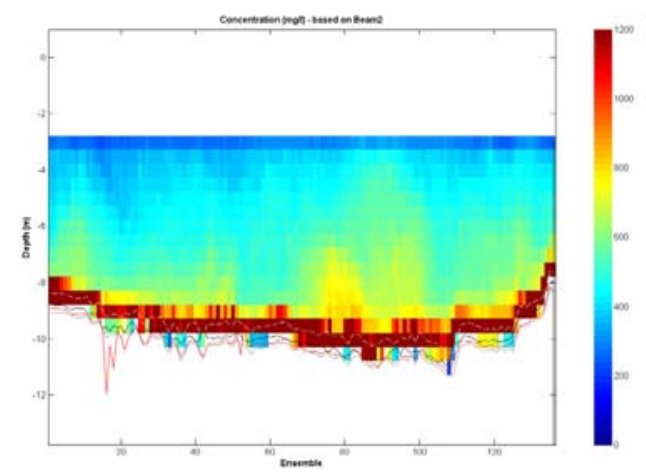

Fig. 13: Concentrations at the first part of the flood period.

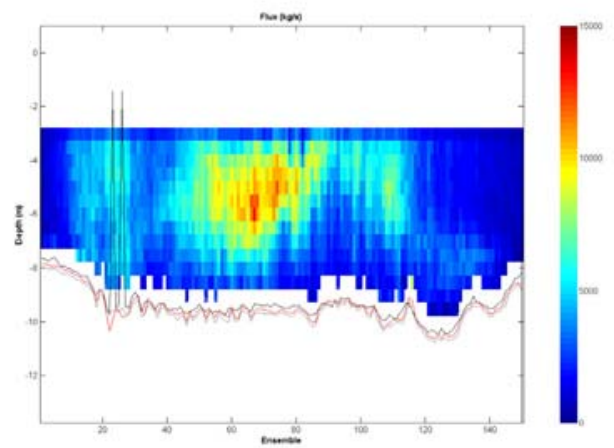

Fig. 14: Sediment fluxes at the second part of the ebb period.

This situation remains relatively stable for the first half of the ebb period. Then the sediment concentrations increase at both sides of the river to approximately $500 \mathrm{mg} / \mathrm{l}$. Within one hour the concentrations increase to more than $2000 \mathrm{mg} / \mathrm{l}$ near the riverbed. During the remaining part of the ebb period the high concentrations spread from the near-bed zone through almost the entire water column. The results consistently show that the concentrations in the middle of the river are lower than at the sides.

This may be the result of the sediment being supplied from the riverbanks. At the end of the ebb period sediment concentrations higher than $2000 \mathrm{mg} / 1$ occur in the greater part of the water column. Within a relatively short period of half an hour the concentrations decrease to below $1000 \mathrm{mg} / \mathrm{l}$ at the beginning of the flood period. 


\subsection{Fluxes}

During the maximum flood current sediment fluxes up to $2000 \mathrm{~g} / \mathrm{m}^{2} / \mathrm{s}$ occur. Towards the end of the flood period the fluxes decrease to lower than $500 \mathrm{~g} / \mathrm{m}^{2} / \mathrm{s}$. After high tide the fluxes remain relatively low $\left(<500 \mathrm{~g} / \mathrm{m}^{2} / \mathrm{s}\right)$ until halfway the ebb period. As a result of increasing velocities and concentrations fluxes increase up to $4000 \mathrm{~g} / \mathrm{m}^{2} / \mathrm{s}$ occur in a small part at the east side of the river. During the remaining part of the ebb period the high fluxes expand over a greater part of the water column. At the end of the ebb period the fluxes decrease to $500 \mathrm{~g} / \mathrm{m}^{2} / \mathrm{s}$ at low tide. In the first part of the flood period, fluxes of $1500 \mathrm{~g} / \mathrm{m}^{2} / \mathrm{s} \mathrm{occur}$.

\section{Discussion}

Although designed for current measurements, ADCPs can accordingly be used for obtaining information on the suspended sediment concentration. The used methods for converting ADCP backscatter to sediment concentrations can only be applied in the Rayleigh regime. The use of a $600 \mathrm{kHz}$ ADCP system limits the Rayleigh regime to grain sizes of $0-800 \mu \mathrm{m}$. Figure 10 presents typical grain size distributions of the suspended sediments in the Weser as measured with the LISST system. The grain size distributions show that the monitored sediment in the Weser meets the Rayleigh regime and that the used conversion method is valid.

Compared to optical devices, ADCPs have the advantage of yielding SSCs over the depth range that is ensonified, at a high temporal and spatial resolution. ADCPs are non-intrusive as the sediment suspension is being monitored at distance. The disadvantage of the acoustic approach is the dependence on sediment properties. In particular, irregularities of the grain size distribution restrict the accuracy of acoustic sediment measurements. For this reason grain size distributions were measured by the LISST system and used for post-processing the data. Applying the LISST data results in more accurate processing. In comparison with the default grain size distribution the sediment attenuation is lower as a result of the LISST grain size distribution. However, because the sediment absorption is a part of the total absorption, the results are not changed significantly by taking the LISST data into account. The resulting concentrations are slightly lower in comparison with the results based on the default grain size distribution. The correlation between the ADCP backscatter and the water sample results varies with time. From this can be concluded that changing sediment properties are of relevant interest and should be taken into account if possible. However, the used method uses high resolution (both temporal and spatial) calibration data as input and meets the latest standards in the field of SSC monitoring. This study showed, despite the LISST input, a variable relation between the acoustic backscatter and the water samples. Most likely changing sediment shapes cause these variations. Unfortunately, there is not a simple instrument that can measure the sediment shape in real-time. Regarding the results 
of the Weser measurements the used method has been proven to be a fast and reliable method for SSC monitoring. During the measurement all used sensors showed their value. All the relations between the resulting backscatter and water samples showed a good correlation.

\section{Conclusions}

Because of its high temporal and spatial resolution, an ADCP is a very usable tool for measurements of sediment concentrations and fluxes. The additional input of grain size distributions from the LISST instrument did not change the results significantly. Variable sediment shapes probably cause the variable relation between ADCP backscatter and water sample results. The separate relations between backscatter and water samples have a good correlation.

\section{Acknowledgements}

The presented case study concerns a field measurement campaign that has been organized by the coastal department of the German 'Bundesanstalt für Wasserbau' (BAW). The authors wish to thank Mr. Christian Maushake for his cooperation and permission to present these results.

\section{$8 \underline{\text { References }}$}

DEINES, K. L. (1999): Backscatter Estimation Using Broadband Acoustic Doppler Current Profilers. - In: Oceans 99 MTS/IEEE Conference Proceedings. San Diego, USA.

FRANÇOIS, R.E. \& G.R. GARRISON (1982a): Sound Absorption Based on Ocean Measurements. - Part I: Pure Water and Magnesium Sulfate Contributions. Journal of the Acoustic Society of America, Vol. 72, pp. 896-907.

FRANÇOIS, R.E. \& G.R. GARRISON (1982b): Sound Absorption Based on Ocean Measurements. - Part II: Boric Acid Contribution and Equation for Total Absorption. Journal of the Acoustic Society of America, Vol. 72, pp. 1870-1890.

LYNCH, J.F. et al. (1994): Determining Suspended Sediment Particle Size Information from Acoustical and Optical Backscatter Measurements. Journal of Continental Shelf Research, Vol. 14, No. 10/11, pp. 1139-1165.

MEDWIN, H. \& C.S. CLAY (1998): Fundamentals of Acoustical Oceanography. - Academic Press. 
RAYLEIGH, L.J.W.S. (1945): The Theory of Sound. - Vol. 1 and 2. New York Dover Publications.

UNESCO (1981): The Practical Salinity Scale 1978 and the International Equation of State of Seawater 1980, Tenth Report of the Joint Panel on Oceanographic Tables and Standards. - Marine Science No. 36, 25pp., UNESCO, Paris.

URICK, R.J. (1948): The absorption of sound in irregular particles. - Journal of the Acoustic Society of America, Vol. 20, No. 3, pp. 283-289.

URICK, R.J. (1983): Principles of Underwater Sound. - Third Edition, McGrawHill Book Company, New York.

VAN RIJN, L.C. (1993): Principles of Sediment Transport in Rivers, Estuaries and Coastal Seas. - Aqua Publications, Amsterdam. 